\title{
Analysis of the Crystallographic Microtexture of a UNS S32205 and a UNS S32304 Duplex Stainless Steels After Cold Rolling and Heat Treatment
}

\author{
Karina Aparecida Martins Barcelos Gonçalves ${ }^{a *}$, Dagoberto Brandão Santos ${ }^{a}$,
}

\author{
Tarcísio Reis de Oliveira ${ }^{b}$
}

\author{
${ }^{a}$ Departamento de Engenharia Metalúrgica e de Materiais, Universidade Federal de Minas Gerais, \\ Belo Horizonte, $M G$, Brasil \\ ${ }^{b}$ Aperam South América, Timóteo, MG, Brasil
}

Received: September 27, 2017; Revised: May 08, 2018; Accepted: June 08, 2018

\begin{abstract}
Samples of duplex stainless steel 32205 (standard duplex) and 32304 (lean duplex) were investigated in the as-received state, cold rolling (with thickness reduction of $64 \%$ and $62 \%$ respectively) and after annealing at $1055^{\circ} \mathrm{C}$ for $20 \mathrm{~s}$ soaking. Crystallographic microtexture was obtained via Electron BackScatter Diffraction (EBSD) technique. The results showed that the crystallographic microtexture of ferrite phase in the as-received, cold rolled and annealed condition were more intense in alpha fiber $=<011>/ / \mathrm{RD}$ and tetha fiber. The austenite microtexture was shown to be, for all conditions, mainly composed by Brass component.
\end{abstract}

Keywords: Duplex Stainless Steel (DSS), crystallographic microtexture, cold rolling, annealing.

\section{Introduction}

Duplex stainless steels (DSS) are characterized by a roughly equal two-part microstructure of austenite (y) and ferrite $(\delta)$. The main application of duplex stainless steels is in the oil \& gas and chemical industries due to their combination of high resistance to pitting corrosion and stress corrosion in environments containing chlorides as well as their high strength in combination with good toughness. ${ }^{1,2}$ The two-phase structure of duplex stainless steels is produced from the correct balance and proper processing between the elements that stabilize the ferrite, known as alphageneous (Mo, $\mathrm{Ti}, \mathrm{Nb}, \mathrm{Si}, \mathrm{Al}$ ), and the elements that stabilize the austenite, known as gammageneous $(\mathrm{Ni}, \mathrm{Mn}$, $\mathrm{C}, \mathrm{N}$ ). Thus, the addition of elements aiming at increasing the resistance to corrosion leads to the stabilization of one or other phase, which may result in different mechanical behavior. ${ }^{3,45}$ According to Michalska and Sozanka ${ }^{6}$, good properties of duplex stainless steels are related to their microstructure which allows a mixture of the properties from the ferritic and austenitic phases. High mechanical strength and high corrosion resistance comes from the contribution of the ferritic phase, while the austenitic phase influences the ductility and the uniform corrosion resistance. In the case of DSS, Keichel et $a l^{7}$ and Reick et $a l^{8}$ reported a reduction in the thickness of elongated ferrite and austenite lamellae in the rolling direction. The ferrite presents lamellae with a lower thickness than austenite after high deformations, because the smaller number of slip systems and the low stacking fault energy (SFE) promote a higher hardening rate of the austenitic phase. For this reason, the deformation is more concentrated in the ferritic phase. In addition to the microstructural changes mentioned above, during the plastic deformation process it is also necessary to consider the effect of the ferrite and austenite phase grain boundaries on the movement and generation of dislocations. ${ }^{9}$ During the annealing process the metallic materials will acquire a microstructure of equiaxial grains and low density of dislocations. ${ }^{10}$ All processes reported above will affect the crystallographic microtexture for each phase present in duplex stainless steel, their grain size distribution and grain morphology. ${ }^{11,12}$

Keitchel, Foct and Gottstein ${ }^{7,13}$ studied the evolution of the crystallographic texture of cold-rolled and annealed duplex stainless steel. The results for the cold rolled sample with $90 \%$ thickness reduction and chemical composition $(25.2 \% \mathrm{Cr}, 0.4 \% \mathrm{~N}, 7.1 \% \mathrm{Ni}, 4.1 \% \mathrm{Mo}$ and $2.9 \% \mathrm{Mn})$ showed that the ferritic phase presented higher intensity in the $\alpha$-fiber from $\{001\}<110>$ and $\{112\}<110>$ and the $\gamma$-fiber was poorly developed. The austenitic phase presented the Brass $=\{110\}<112>$ and Goss $=\{110\}<001>$ components with higher intensity. The authors concluded that the microtexture of austenite and ferrite in DSS is similar to the one found in austenitic and ferritic stainless steels. After to hot and cold rolling the samples were annealed either at $1050^{\circ} \mathrm{C}$ and subsequently water quenched. The texture development during annealing of the austenite phase in the DSS resulted in a texture different from single phase austenite, for the ferritic phase the texture shows mainly recovery, i.e. retained rolling texture, with little indication of recrystallization. According to the authors, the annealing behavior of cold rolled DSS has been affected by the presence of the two phases. The layered grain morphology in DSS affects the nucleation conditions for recrystallization, and the high SFE of ferrite favor recovery 
over recrystallization during annealing. Same results have been reported in literature ${ }^{14,15}$

The DSS studied in the present work are UNS S32205 / S31803 and UNS S32304. The S32205 has a greater number of alloying elements, specially molybdenum (Mo) that improves the properties such as corrosion resistance, since DSS S32304, called lean steel with lower molybdenum and nickel content, presents better resistance to corrosion compared to austenitic stainless steel 304L. ${ }^{16}$

Knowing microstructural evolution during cold deformation may lead to a better understanding of the mechanisms acting during the annealing process, recovery and / or recrystallization. Cold reduction leads to microstructural change due to the plastic deformation that occurs in the metals. The grains are more elongated, an increase occurs in the grain boundary area and substructures are formed inside the grain. It is worth mentioning other parameters that may influence the deformation mechanism, be they stacking failure energy (SFE), temperature and strain rate..$^{10,12}$

The main effects of the cold rolled microstructure in the DSS S32304 are characterized by the refine of the grain structure, shear bands ${ }^{17,18}$ and sometimes to induce microstructural changes. Many authors ${ }^{19,20}$ have investigated the formation of strain-induced martensite due to plastic deformation in this material.

The processing route manufacture DSS sheets generally consist in alternative steps of rolling and annealing. Such process steps the steel undergoes microstructural changes, which affect the mechanical properties of the final product. ${ }^{12}$ For example, gas transportation tube are fabricated from hot rolled and annealed sheets. Their texture can be modified during deformation, recrystallization and phase transformations that occurring in each phase $(\delta / \gamma)$ at various stages of the thermomechanical treatment. ${ }^{7,11}$ The texture development of cold rolled and annealed austenitic and ferritic stainless steels has been studied. Therefore the need to understand the behaviour of the crystallographic texture in duplex stainless steels S32304 and S322505.,21 The texture components observed in ferritic single phase steel are composed of the $\gamma$ fiber $=<111>/ / \mathrm{ND}$ (normal direction), $\alpha$ fiber $=<011>/ / \mathrm{RD}$ (rolling direction) and the rotated cube component. In austenitic single phase steel the components Brass $\{110\}<112>$, Goss $\{110\}<001>$ and Cube $\{100\}<001>$ are referred. ${ }^{18}$ However, the evolution of crystallographic texture in metals with two-phase structure, as in the case of DSS, is affected during rolling by the compatibilization (distribution) of the change between the two phases and mainly by the presence of ferrite/austenite boundaries, which may restrict crystallite rotation, reducing the effect of deformation on texture changes. ${ }^{13}$ The limitations caused by the banding morphology in the microstructure of the DSS also affect the texture evolution in the recrystallization process, as the strengthening of the $\gamma$-fiber in the ferrite and the cube component in the austenite, does not occur in a marked way. The new grains formed in both phases during the recrystallization process maintain the prior orientation of deformation and fragmentation of the fibers into individual components observed. ${ }^{22}$ The knowledge about of the microstructural changes and texture evolution which can occur during of the rolling and aneealing process is necessary for the undestanding of its influence on the final mechanical properties. ${ }^{11,12,21}$ Data provided by the analysis of crystallographic texture are used as an input in a simple micromechanical model for the correct choice of heat treatment that was proposed by Badji et al. ${ }^{2}$ for decrease the degree of heterogeneity to obtain good final mechanical properties.

\section{Experimental}

The materials studied in the present work were S32304 and S32205 DSS. These materials were industrially processed and supplied by Aperam South America with a thickness of 4.08 and $4.26 \mathrm{~mm}$ respectively in the condition of hot rolled and annealed, however, for better understanding it is called as-received. The chemical composition of both steels is reported in Table 1. The main diference in chemical composition between the DSSs is the Mo content, where S32205 DSS has $2.628 \%$, while the S32304 lean DSS has $0.275 \%$. There is also a lower N, Mn, and Ni content in S32304. The samples were cold rolled (CR) with thickness reduction of 62 and $64 \%$ for S32304 and S32205, respectively, to a final thickness of $1.53 \mathrm{~mm}$ (given in Table 2). The cold rolling was performed using a manual pilot mill, model 4.085 from the manufacturer FENN. The cold rolled samples were then annealed in a muffle furnace at $1050^{\circ} \mathrm{C}$, with a coupled thermocouple for temperature control in the middle of the samples.

After 20 seconds of soaking the samples were removed from the oven and immediately quenched in freezing water. The longitudinal (rolling direction plane) sections of the samples were considered. Metallographic samples were prepared by conventional grinding and polishing, followed by a $0.05 \mu \mathrm{m}$ colloidal silica.

The microstructure development was investigated by optical microscopy (OM) and scanning electron microscopy (SEM/EBSD). From the images acquired in the optical microscope, the phases were quantified using the grid test according to ASTM E562 standard. The ThermoCalc software,

Table 1. Chemical composition of S32304 and S32205 duplex stainless steels (weight percent).

\begin{tabular}{lcccccccccc}
\hline Steel & C (\%) & Cr (\%) & Ni (\%) & Mo (\%) & N (\%) & Mn (\%) & Cu (\%) & Si (\%) & S (\%) & P (\%) \\
\hline S32304 & 0.011 & 22.87 & 4.20 & 0.275 & 0.1193 & 1.45 & 0.453 & 0.2013 & 0.0004 & 0.0215 \\
$\mathbf{S 3 1 8 0 3}$ & 0.013 & 22.44 & 5.31 & 2.628 & 0.1534 & 1.80 & 0.241 & 0.3815 & 0.0005 & 0.0294 \\
\hline
\end{tabular}


Table 2. Parameters used in cold rolling a) S32304 and b) S32205.

\begin{tabular}{ccccccc}
\hline & \multicolumn{3}{c}{ S32304 } & \multicolumn{3}{c}{ S32305 } \\
\hline Passe number & $\begin{array}{c}\text { Initial Thickness } \\
(\mathrm{mm})\end{array}$ & $\begin{array}{c}\text { Final Thickness } \\
(\mathrm{mm})\end{array}$ & Strain $(\%)$ & $\begin{array}{c}\text { Initial Thickness } \\
(\mathrm{mm})\end{array}$ & $\begin{array}{c}\text { Final Thickness } \\
(\mathrm{mm})\end{array}$ & Strain $(\%)$ \\
\hline 1 & 4.08 & 3.33 & 18 & 4.26 & 3.38 & 21 \\
2 & 3.33 & 2.78 & 32 & 3.38 & 2.84 & 33 \\
3 & 2.78 & 2.35 & 42 & 2.84 & 2.40 & 44 \\
4 & 2.35 & 2.03 & 50 & 2.40 & 2.04 & 52 \\
5 & 2.03 & 1.75 & 57 & 2.04 & 1.76 & 58 \\
6 & 1.75 & 1.53 & 62 & 1.76 & 1.53 & 64 \\
\hline
\end{tabular}

together with the TCFE-4 database, was used to predict the formation of possible phases as a function of temperature and chemical composition (Table 1).

Electron BackScatter Diffraction (EBSD) characterization was performed to obtain crystallographic texture of the samples in the as-received state, cold rolled and annealed. The analyzes were performed in a scanning electron microscope with tungsten (W) filament, FEI brand, model Inspect S50. The cold rolled samples measurements were done in a high resolution scanning electron microscope with tungsten monocrystal filament - FEG, model Quanta FEG 200 - FEI. The textures were quantitatively examined using the orientation distribution function (ODF) obtained from the OIM (orientation imaging microscopy) software.

\section{Results and Discussion}

\subsection{Microstructural evolution of the duplex stainless steels S32304 and S32205}

The microstructure evolution from the as-received samples to cold rolling and annealing are presented in Figure 1 and 2 for the DSS's S32304 and S32205, respectively. The micrographs show the typical microstructures of the DSS with the $\delta$-ferrite phase (darker phase) and $\gamma$-austenite phase (lighter phase) elongated in the rolling direction. After deformation, the austenite and ferrite phases are characterized by typical banded structure of alternating austenite and ferrite, elongated in the rolling direction. Shear bands were observed in the samples with $62 \%$ and $64 \%$ thickness reduction in cold, which are characteristic of deformed materials and form angles of approximately 30 to $60^{\circ}$, being the $35^{\circ}$ angle more frequently cited in literature. ${ }^{17}$ Figure 3 shows the phase diagram obtained by means of thermodynamic calculations obtained by Thermo-Calc $\AA$ software using the chemical composition of the samples, Table 1 . It is important to note that the calculations obtained represent the equilibrium conditions. Based on the Thermocalc results, it is possible to observe the presence of the sigma phase and carbides below $850^{\circ} \mathrm{C}$. Above this temperature only ferrite and austenite phases are present in the DSS. The ideal ratio of the $50 / 50 \%$ of ferrite and austenite balance is obtained at a temperature of approximately $1100^{\circ} \mathrm{C}$, as shown in Figure $3 .^{15,23}$ In order to validate the results obtained from the thermodynamic calculations, phase quantification was carried out according to ASTM E562. The counting was performed in 40 random fields using a circular transparent matrix with 24 points. The results are presented in Figure 4. The DSS in the as-received condition were solubilized after hot rolling according to the manufacturer's information. It is important to mention that the results of the volumetric fraction of both phases showed evidence of $\alpha^{\prime}$-martensite

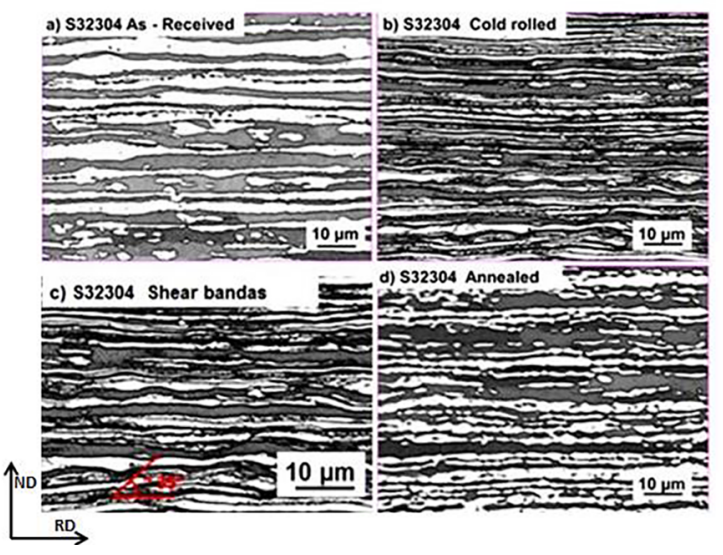

Figure 1. Microstructure of the duplex stainless steels S32304; a) as received, b) cold rolled (CR) and c) annealed

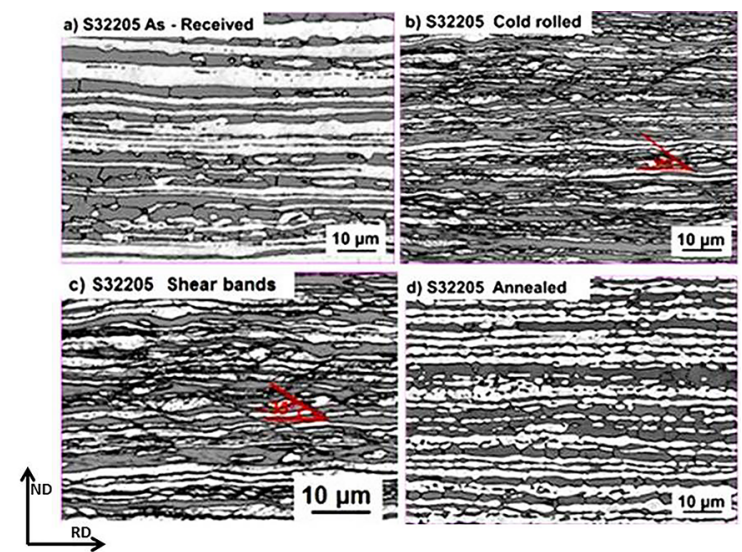

Figure 2. Microstructure of the duplex stainless steels S32205; a) as received, b) cold rolled (CR) and c) annealed 
a) $\$ 32304$

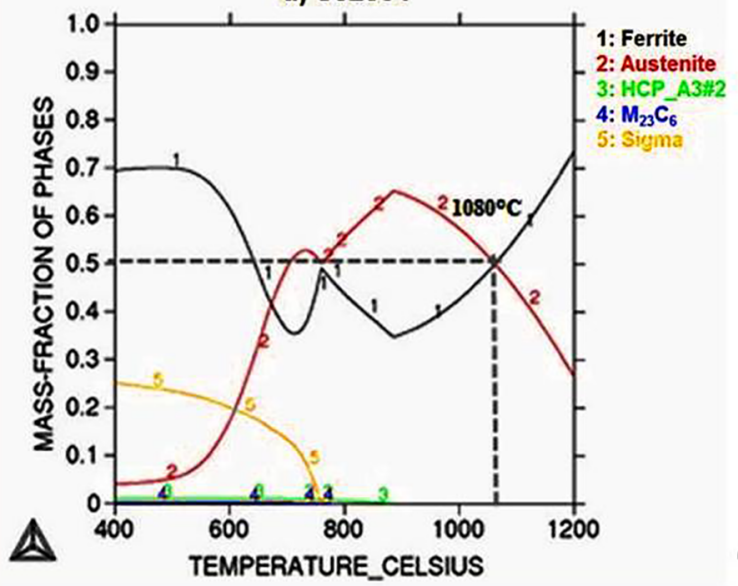

b) $\$ 32205$

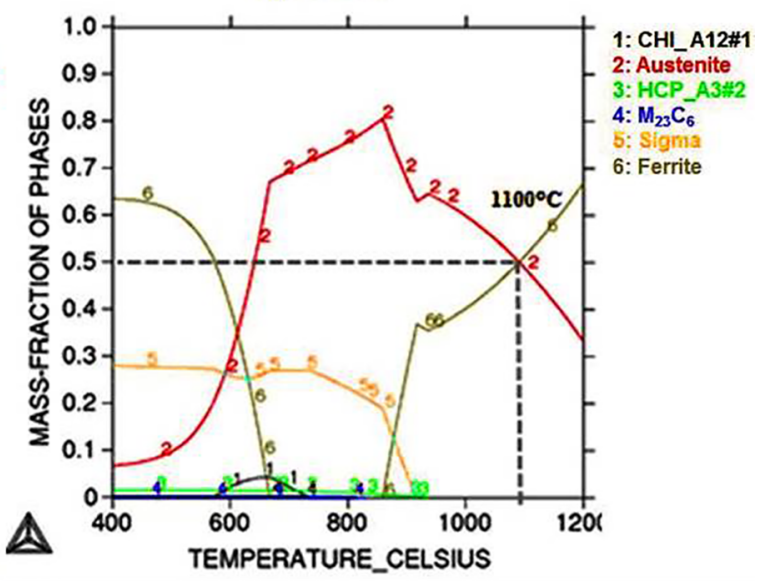

Figure 3. Duplex stainless steels phase equilibrium diagram; a) S32304 and b) S32205
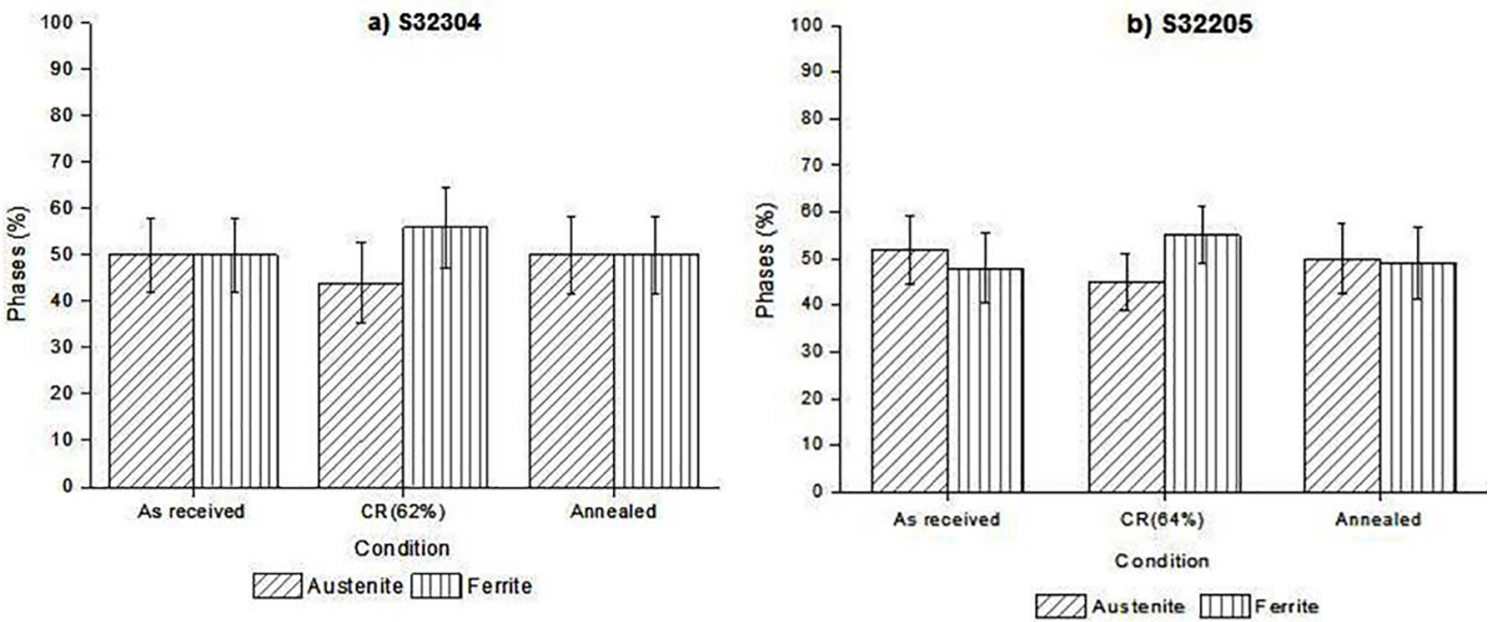

Figure 4. Percentage of the austenitic and ferritic phases of duplex stainless steels; a) S32304 and b) S32205

in the cold deformed samples (62 and $64 \%$ ) interfering in the perfect identification of the austenitic and ferritic phases during the phase quantification. Similar analyzes has been carried out by other authors ${ }^{15,23}$ who found $\alpha^{\prime}$-martensite in the deformed samples.

\subsection{Microtexture of the duplex stainless steels S32304 and S32205}

From these EBSD orientations results, the orientation distribution functions can be calculated for both phases. These orientations are presented and characterized by the classical Miller indices $\{h \mathrm{kl}\}<\mathrm{uvw}>$ where, $\{\mathrm{hkl}\}$ and $<\mathrm{uvw}>$ are the indices of the rolling plane and direction respectively. For the austenitic and ferritic phases used in this study, the $\varphi_{2}=0,45$ and $65^{\circ}$ and $\varphi_{2}=0$ and $45^{\circ}$, sections of the Euler space are shown the Figure 5 and 6 respectively.

In the as-received samples, the main component observed in austenite is Brass $=\{110\}<112>$ belonging to $\beta$-fiber. In lower intensity, it is observed the presence of the components
$\mathrm{S}=\{123\}<634>, \mathrm{Cu}=\{112\}<111>$ and $\mathrm{cube}=\{100\}<001>$. The cube component is typical of metals with FCC crystalline structure with high SFE in the recrystallized condition. ${ }^{15}$ The ferrite texture is mainly constituted of an $\alpha$ fiber $=<110>/ /$ $\mathrm{RD}$ with high intensity on the rotated cube $=\{001\}<110>$, besides a weak $\gamma$ fiber $=<111>/$ ND was found. The results about crystallographic textures was similar for all conditions analyzed according Figures 5 and 6.

Results obtained in a DSS base metal sample S32205 analyzed by Badji et al. ${ }^{21}$ also report similar behavior in the crystallographic microtexture for ferrite and austenite. After cold deformation, it is observed a strengthening of the $\alpha$-fiber and the development of the $\gamma$-fiber in the ferrite. In the austenite it is observed the weakening of the cube component and a strengthening in the Brass, $\mathrm{S}$ and $\mathrm{Cu}$ component.

The texture of the ferritic and austenitic phase after cold rolling showed good agreement with the results reported in literature..$^{7,8,13,15,23}$ It is also observed coherence in the crystallographic microtexture after thermally treated. In the 


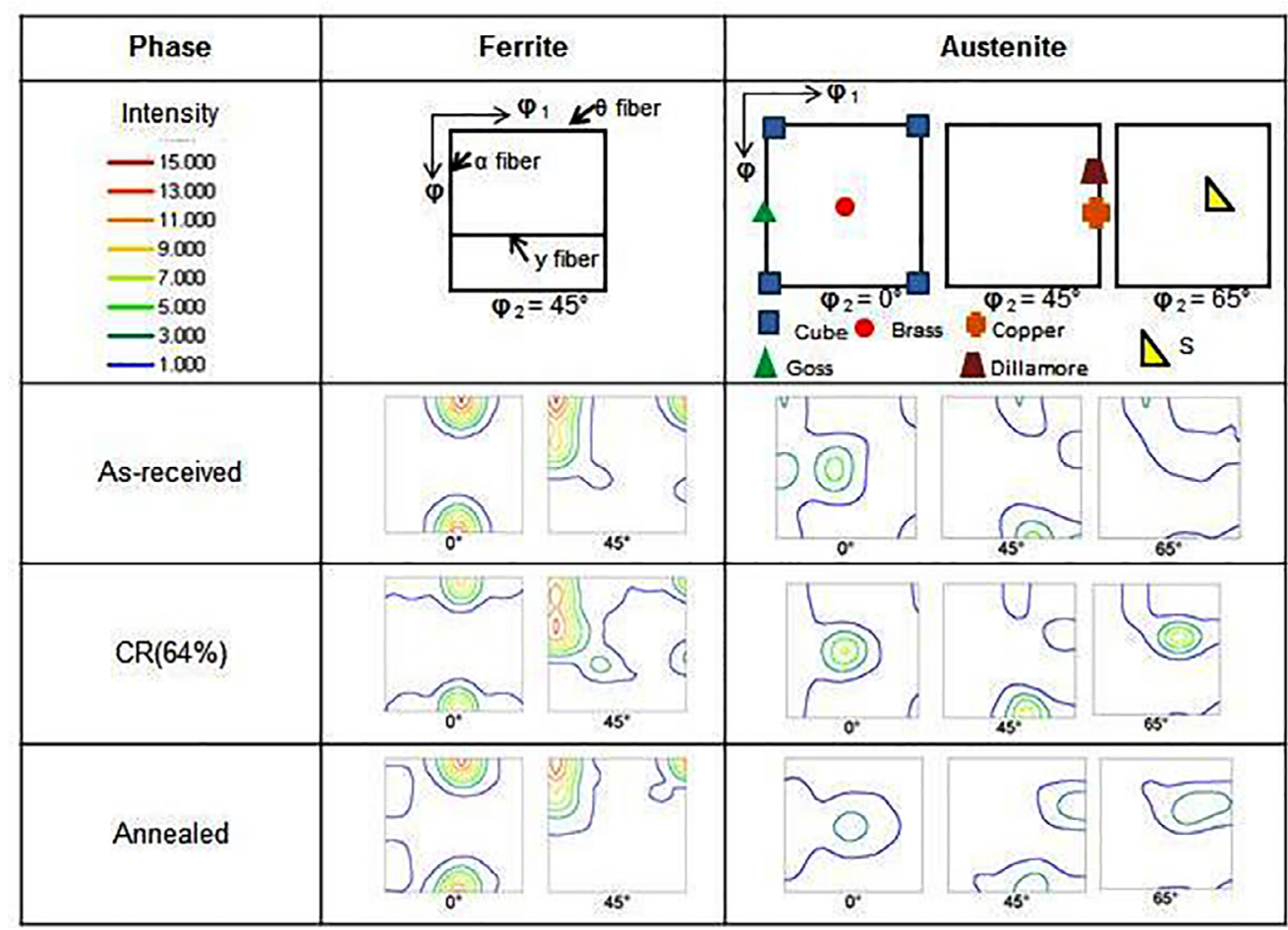

Figure 5. Crystallographic microtexture of duplex stainless steels S32205 of the samples as received, cold rolled and annealed

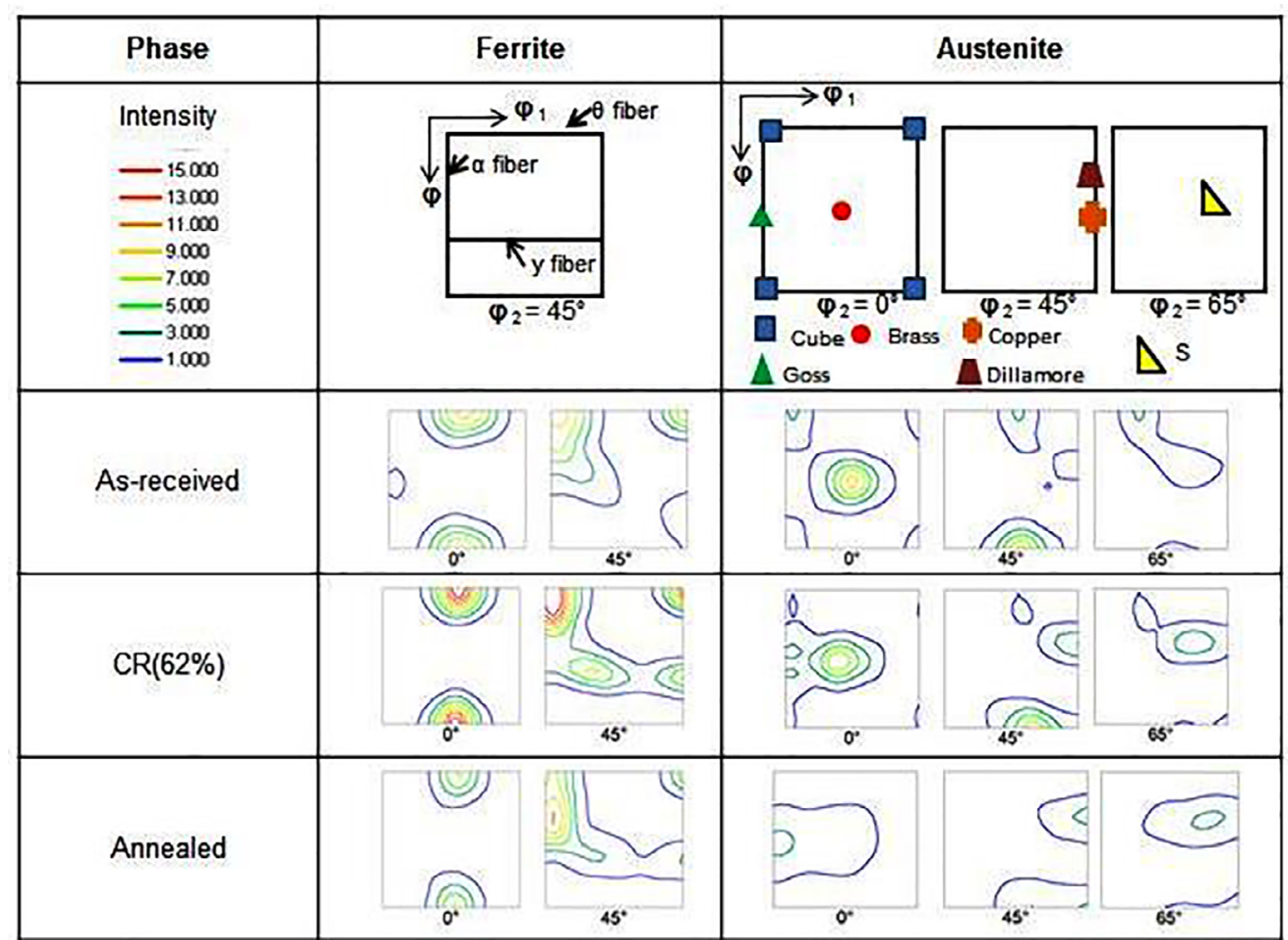

Figure 6. Crystallographic microtexture of duplex stainless steels S32304 of the samples as received, cold rolled and annealed 
ferrite, the components that were present in the samples asreceived and cold rolled did not show great changes in the values of their intensities and in the austenite it was observed that the complete recrystallization promoted the general weakening of the texture. All the results discussed from this work on the behavior of the fibers present in the ferritic phase can be visualized in the Figure 7 for each condition of the samples. Ferrite texture in the studied conditions showed higher volumetric fraction in the $\alpha$-fiber for all conditions, for both samples. It is observed that with the increase of the cold deformation there was an increase in the intensities of the components belonging to this fiber, which was already expected because is the fiber of higher stability in the rolled ferrite. The $\gamma$-fiber was weakly developed in all analyzes, presenting volumetric fractions close to the samples under their different conditions. According to Keichel et al. ${ }^{7,13}$ the development of $\gamma$-fiber is observed with a strong development of the $\{111\}<112>$ component. The components $\{111\}$ $<110>$ and $\{111\}<112>$ store higher energy during rolling, thus, they have more favorable conditions for nucleation and grain boundary movement. However, in the experiments carried out ${ }^{7,13}$ on duplex stainless steels, this behavior was not observed due to the low intensity of $\gamma$-fiber from the annealed and hot rolled coil. Keitchel et al.$^{7,13}$ and Badji ${ }^{11}$ reported in their studies that the high shear failure energy of the ferrite favors the dynamic recovery process during the hot rolling of the DSS. The low stored energy of the components $\{001\}$ $<110>$ to $\{112\}<110>$, are characteristics of recovery during annealing. It is worth mentioning that Moura ${ }^{15}$ stated that the complete recrystallization and transition of $\alpha$-fiber to $\gamma$-fiber in ferritic phase does not occur even after anneling at higher temperatures than the ones used for monophasic steels. Thus, after hot rolling and annealing the ferrite will present recovered and recrystallized grains. From these results, it is observed that the general behavior of the crystallographic texture of the ferritic and austenitic phases after processing steps described in this work are in agreement with the results already reported in the literature for DSS. $7,8,21,23,24$

\section{Conclusions}

- The volume fraction of the phases in the asreceived samples and annealed remained close and coherent values, since they were thermally treated at $1055^{\circ} \mathrm{C}$ where the fractions of both phases are in thermodynamic equilibrium.

- After cold deformation, the samples presented small changes in microtexture in comparison to the asreceived samples. The $\alpha$-fiber in ferrite presented higher volumetric fraction, while the $\gamma$-fiber remained with low intensity. The Brass component in austenite remained with higher intensity and no cube component was present.

- The ferrite microtexture showed characteristic of recovery and recrystallization after anneling. The austenite lamellaes prevent grain nucleation and grain growth at the $\gamma$-fiber suppressing the grain growth at $\alpha$-fiber which explains the transition from $\alpha$-fiber to $\gamma$-fiber and the incomplete recrystallization.

- The austenite phase microtexture did not present significant changes after annealing.

\section{Acknowledgments}

The authors would like to acknowledge Aperam South America for the technical support and for providing the material for this study. KAMBG would like to thank CAPES
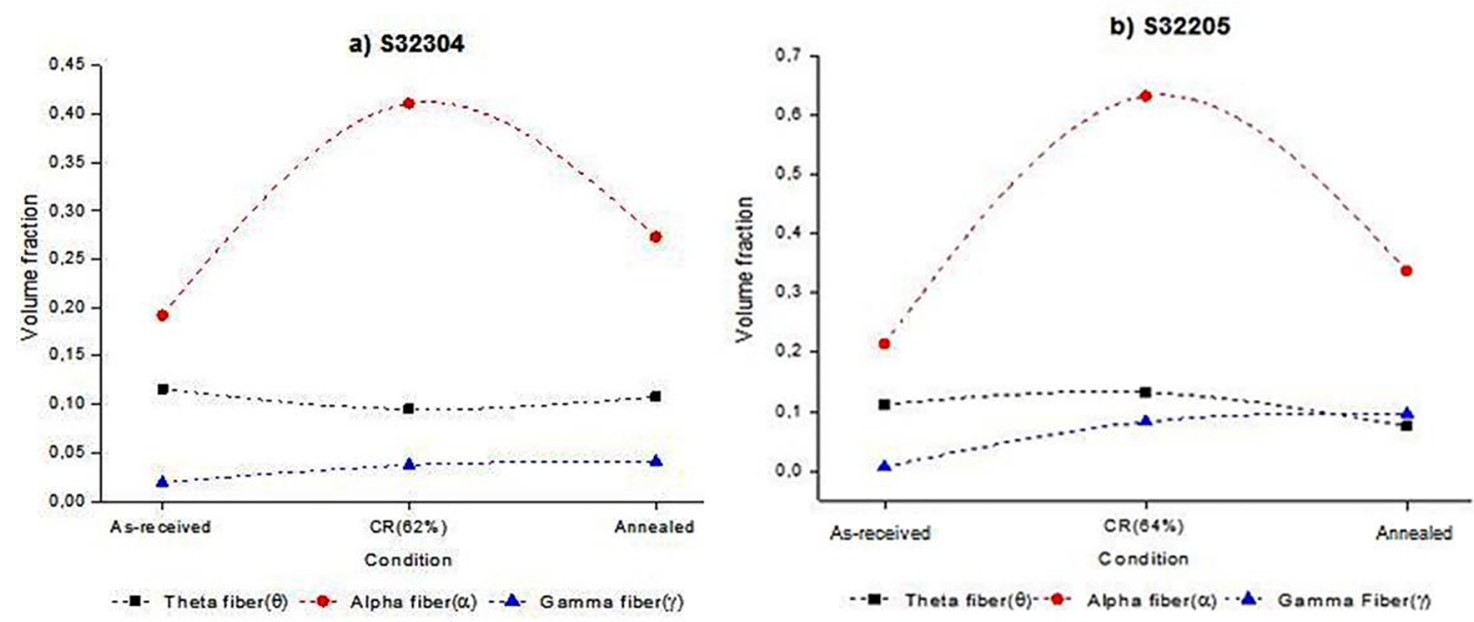

Figure 7. Volume fraction fiber of the phase ferritic of the duplex stainless steels: a) S32304 and b) S32205 
support and DBS would like to thank CAPES, CNPQ and FAPEMIG institutions for granting academic scholarships

\section{References}

1. Weisbrodt-Reisch A, Brummer M, Hadler B, Wolbank B, Werner EA. Influence of temperature, cold deformation and a constant mechanical load on the microstructural stability of a nitrogen alloyed duplex stainless steel. Materials Science and Engineering: A. 2006;416(1-2):1-10. DOI: https://doi. org/10.1016/j.msea.2005.09.117

2. Badji R, Bouabdallah M, Bracoix B, Kahloun C, Belkessa $\mathrm{B}$, Maza H. Phase transformation and mechanical behavior in annealed 2205 duplex stainless steel welds. Materials Characterization. 2008;59(4):447-453. DOI: https://doi. org/10.1016/j.matchar.2007.03.004

3. Solomon HD, Devine TM Jr. Duplex stainless steels: a tale of two phases. In: Conference of the Duplex Stainless Steels; 1982; Saint Louis, MO, USA. Ohio: ASM; 1982. p. 693-756.

4. Wronski S, Tarasiusk J, Bacroix B, Baczmanski A, Braham C. Investigation of plastic deformation heterogeneities in duplex steel by EBSD. Materials Caracterization. 2012;73:52-60. DOI: http://dx.doi.org/10.1016/j.matchar.2012.07.016

5. Badeshia HK, Honeycombe RW. Steels Microstructure and Properties. Chapter 12. $3^{\text {rd }}$ ed. Oxford: Butterwoth-Heinemann; 2006.

6. Michalska J, Sozanska M. Qualitative and quantitative analysis of $\sigma$ and $\chi$ phases in 2205 duplex stainless steel. Materials Caracterization. 2006;56(4-5):355-362.

7. Keichel J, Foct J, Gottstein G. Deformation and Annealing Behavior of Nitrogen Alloyed Duplex Stainless Steels. Part I: Rolling. ISIJ International. 2003;43(11):1781-1787.

8. Reick W, Pohl M, Padilha AF. Determination of stacking fault energy of austenite in a duplex stainless steel. Steel Research. 1996;67(6):253-256. DOI: 10.1002/srin.199605486

9. Fréchard S, Martin F, Clément C, Cousty J. AFM and EBSD combined studies of plastic deformation in a duplex stainless steel. Materials Science and Engineering: A . 2006;48(1-2):312319 .

10. Humphreys FJ, Hatherly M. Recrystallization and Related Annealing Phenomena. $2^{\text {nd }}$ ed. Oxford: Elsevier; 2004. 658 p.

11. Badji R, Chauveau T, Bracoix B. Texture, misorientation and mechanical anisotropy in a deformed dual phase stainless steel weld joint. Materials Science and Engineering: A. 2013;575:94103.
12. Fargas G, Akdut N, Anglada M, Mateo A. Microstructural Evolution during Industrial Rolling of a Duplex Stainless Steel. ISIJ International. 2008;48(11):1596-1602.

13. Keichel J, Foct J, Gottstein G. Deformation and Annealing Behavior of Nitrogen Alloyed Duplex Stainless Steels. Part II: Annealing. ISIJ International. 2003;43(11):1788-1794.

14. Souza Júnior CM. The influence of deformation and thermal treatment on the crystallographic texture of a duplex stainless steel. [Thesis]. Rio de Janeiro: COPPE/Federal University of Rio de Janeiro; 2008. 143 p.

15. Moura AN. Estudo da evolução microestrutural e das propriedades mecânicas do aço inoxidável duplex UNS S32304 durante o recozimento final. [Dissertation] Vitória (ES): Federal Institute of Espírito Santo; 2016. 161 p.

16. Charles J. Duplex stainless steel, a review after DSS'07 held in Grado. Revue de Métallurgie. 2008;105(3):155-171.

17. Padilha AF, Siciliano Jr F. Encruamento, recristalização, crescimento de grão e textura. $3^{\mathrm{a}}$ ed. São Paulo: ABM; 2005. $124 \mathrm{p}$.

18. Jura J, Baudin T, Mathon MH, Swiatnicki W, Penelle R. Microstructure and Texture Analysis in a Cold-Rolled AusteniticFerritic Steel with Duplex Structure. Materials Science Forum. 2002;408-412:1359-1364. DOI: 10.4028/www.scientific.net/ MSF.408-412.1359

19. Baldo S, Mészáros I. Effect cold rolling on microstructure and magnetic properties in a metastable lean duplex stainless steel. Journal of Materials Science. 2010;45(19):5339-5346. DOI: 10.1007/s10853-010-4582-5

20. Bassani P, Breda M, Brunelli K, Mészáros I, Passaretti F, Zanellato M, et al. Characterization of a Cold-rolled 2101 Lean Duplex Stainless Stell. Microscopy and Microanalysis. 2013;19(4):988995. DOI: $10.1017 / \mathrm{S} 1431927613001426$

21. Badji R, Bacroix B, Bouabdallah M. Texture, microstructure and anisotropic properties in annealed 2205 duplex stainless steel welds. Materials Caracterization. 2011;62(9):833-843.

22. Zaid M, Bhattacharjee PP. Electron backscatter diffraction study of deformation and recrystallization textures of individual phases in a cross-rolled duplex steel. Materials Caracterization. 2014;96:263-272.

23. Gauss C. Microstructural evolution of a UNS S32205 duplex stainless steel. Microstructural evolution of a UNS S32205 duplex stainless steel during cold rolling and further annealing. [Dissertation]. Lorena: University of São Paulo; 2015. 167 p.

24. Jimenez JA, Carsi M, Ruano AO, Peñalba F. Characterization of a $\delta / \gamma$ duplex stainless steel. Journal of Materials Science. 2000;35(4):907-915. 